\title{
A Note on the History of the Literature of the Toxæmia of Pregnancy.
}

\author{
By Francis Henry Champneys, M.A., M.D. (Oxon.), F.R.C.P., \\ Physician-Accoucheur to St. Bartholomew's Hospital.
}

THE valuable work contributed by Dr. Whitridge Williams on the "Toxæmias of Pregnancy" has had so large an effect on contemporary thought that I venture to make one or two criticisms, not so much on that work, as on the general statement of the subject as presented by him.

I quote first from the second edition of his "Obstetrics," 1908, p. 509. This work, or rather its first edition, 1903, was accessible before the Bulletin of the Johns Hopkins University in 1906 :

Etiology. "Until comparatively recently our knowledge concerning its ætiology was extremely defective, and even yet our information is not entirely satisfactory. In my monograph upon the subject, in 1906, I stated that the evidence at present available justifies the differentiation of three types of serious vomiting of pregnancy: namely, reflex, neurotic, and toxæmic."

"The reflex variety, as its name implies, results from the presence of abnormalities in other portions of the body, and particularly in the generative tract. Thus, it sometimes happens that it is associated with retroflexion of the uterus or an ovarian tumour, and immediate relief follows the replacement of the uterus or the removal of the tumour."

"Attention was first directed to the neurotic variety by Kaltenbach, who stated in 1891 that the vomiting of pregnancy is usually a manifestation of a neurosis, somewhat allied to hysteria, and is readily amenable to suggestive treatment. Clinical observation affords abundant evidence in favour of such a view, as it is well known that many women, who are apparently upon the verge of death from starvation as the result of vomiting, suddenly become better spontaneously following a threat to induce abortion. Moreover, prompt cure frequently follows the employment of most varied and unscientific treatment, such as the use of an electrical battery which was later found to be entirely out of order, or the application of various medicaments to the cervix, or the use of leeches. Moreover, it may be affirmed that the cures following dilatation of the cervix, as recommended by Copeman, should be regarded merely as due to suggestion."

"In the toxæmic variety, on the other hand, the condition is associated with a profound disturbance of metabolism, which is 
manifested by characteristic changes in the urine and the presence of definite lesions in the liver and kidneys. It was first shown in my clinic that the urine in such cases presents a high ammonia coefficient, indicating that a much greater proportion of total nitrogen is excreted in the form of ammonia than normal. Normally in the first half of pregnancy the ammonia co-efficient varies between 4 and 5 per cent., but in toxæmic vomiting it may rise as high as $10,20,30$, or even 40 per cent., and in one of my cases reached 40 per cent. just before death."

"Matthews Duncan, in 18r9, pointed out that the condition (romiting of pregnancy) was sometimes associated with serious hepatic disorders, but this was not generally recognized until the work of Stone, Ewing and myself showed that in many of the fatal cases lesions were present in the liver identical with those occurring in acute yellow atrophy."

In the Bibliography (page 548) reference is made to "Duncan, Clinical Lecture on Hepatic Diseases in Gynæcology and Obstetrics, London Medical Times and Gazette, 1878, i, pp. 57-59."

This Clinical Lecture was republished in his Clinical Lectures (1st edition, 1879, p. 144) under the heading: "On hepatic disease in gynæcology and obstetrics."

I next quote from the same author: Bulletin of the Johns Hopkins Hospital, vol. xvii, No. 180, March 1906.

The author describes three kinds of vomiting of pregnancy: reflex, neurotic and toxæmic.

Among (1) reflex causes he mentions (a) abnormalities of the uterus, particularly displacements; (b) certain cases of endometritis; (c) ovarian tumours; (d) abnormalities of the ovum, such as hydramnios, hydatidiform mole and certain eases of twin pregnaney.

For his authority as to $(a)$ he quotes Graily Hewitt and others, but expresses his own opinion in very hesitating language as to its general truth. As regards (b) J. H. Bennett is quoted as referring certain cases to inflammatory conditions of the cervix and Copeman as referring certain cases to rigidity of the os internum. Of these also the author speaks sceptically. As regards $(c)$ the statement that ovarian tumours may cause it, the author claims " that in exceptional cases the presence of tumours of the ovaries may accentuate or even cause serious vomiting." As regards (d) "Clinical observation apparently shows that both hydramnios and twin pregnancies predispose to excessive vomiting, though whether this is the result of the mere over-distension of the uterus, or whether it is associated with some toxæmic condition has not yet been demonstrated. Hydatidiform mole has a similar effect."

The very guarded and sceptical manner in which the author expresses himself gives the reader the impression that he does not really believe in his own Class 1 . 
From my own experience I am able to confirm the author's scepticism. I have never, for instance, in 35 years, seen a case of incarceration of the retroverted gravid uterus associated with severe vomiting. Although such a combination may occur, nothing will convince me that such an association of severe vomiting with retroversion of the gravid uterus is anything more than a coincidence. I say the same of the rest of the instances cited, that their association with vomiting is nothing but fortuitous and is not essential.

I would quote the author's own words: "Moreover, prompt cure frequently follows the employment of most varied and unscientific treatment, such as the use of an electric battery which was later found to be entirely out of order, or the application of various medicaments to the cervix, or the use of leeches. Moreover, it may be assumed that the cures following dilatation of the cervix, as recommended by Copeman, should be regarded as due to suggestion."

\section{Neurotic vomiting.}

"Although the effect of pregnancy upon the mental, moral and nervous equilibrium had long been recognized, and Arquétin (1865), Tisserand (1865), Duncan (1879), Rosenthal (1879), Ahlfeld (1891) and others had pointed out that many cases of severe vomiting were neurotic or hysterical in origin, it was nevertheless not until Kaltenbach read his paper before the Berlin Obstetrical Society in $\mathbf{1 8 9 0}$ that general attention was directed to this phase of the subject." (The dates are mine.)

The author gives his reasons for his statement. It may very likely be true that Kaltenbach's writings were the first to strike the general imagination. In any case there can be no doubt of the reality of this class.

\section{Toxcemic vomiting.}

"As far as I have been able to ascertain, Fischl, in 1884, was the first modern writer to suggest the toxæmic character of the condition. . .."

"The following year (1885) Jolly reported two cases of paralysis which occurred in pregnant women suffering from the vomiting of pregnancy, and attributed the former condition (paralysis) to a neuritis which was probably caused by some toxic substance peculiar to pregnancy."

Other authors are mentioned in subsequent years.

Then occurs the following passage: "As early as 1879 Matthews Duncan suggested that the underlying factor, in certain of the fatal cases at least, was acute yellow atrophy of the liver."

"This view . . obtained little if any recognition."

This seems to me a very inadequate statement of the share of Dr. Matthews Duncan in the elucidation of this important and 
obscure subject. I therefore quote the part of his writings which particularly refers to the matters in question. The italics are mine.

"Of the vomiting of pregnancy there are at least two kinds. There is what may be called the common kind, which, when severe, is almost certainly the result of morbid innervation. Whether the sickness and vomiting of pregnancy is a reflected sensation, or a reflected motion, or the result of a reflected sensation, it is a consequence of morbid innervation. It is frequently very grievous and perhaps is sometimes even fatal. This kind of vomiting in pregnancy is arrested when the fotus dies. It is arrested certainly by abortion, miscarriage, or delivery at full time. It is not accompanied by any symptoms of grave disorder, except such as arise from defective nutrition."

"But there is another kind of vomiting in pregnancy, our knowledge of which is extremely imperfect and upon which some remarks are called for. These are cases of vomiting in pregnancy, described by many authors, which prove fatal, sometimes suddenly and unexpectedly, without any apparent cause, or without any suspicion of the cause at the time the historics of such grave cases were written. Along with such cases have to be included some similar cases of sudden and unexpected death after delivery."

"Our knowledge of the physiology of parenchymatous degeneration of the great glands, seems to throw light upon this fatal or extremely dangerous form of vomiting in pregnancy-to show that the vomiting in such cases is something more than a morbid innervation, that it is a symptom of a visible lesion. The case that I am about to read to you I am quite sure, some years ago, I should have regarded as one of vomiting in pregnancy proving fatal. I should not have known how to go any further. But you will find, as I proceed, that I have dealt with that case in an entirely different manner, dèriving my knowledge from recent researches into the nature of a disease called icterus gravis, or what used to be called yellow atrophy of the liver."

Then follows a discussion of the pathology of acute yellow atrophy. "The condition of the blood is probably a chief part of the cause of proneness of women to disease of the kidney and urcemia. ... Now, if you look into the histories of fatal cases of vomiting in pregnancy, and fatal cases of a similar kind occurring just after pregnancy, in the puerperal state, you will find a slight jaundice often mentioned. . . . In order that you may further see how difficult it has been to reach the truth in this matter, I must tell you that cases of this disease occur without jaundice, or with very little. . .."

Then comes a discussion of various kinds of jaundice occurring in pregnancy, ordinary catarrhal jaundice, and that due to acute yellow atrophy. "The disease has been called cholæmic eclampsia, just as the corresponding disease of the kidneys is sometimes called uræmic 
eclampsia, from the frequency of the convulsions. . . . $\Lambda$ great author has suggested that the disease is essentially uræmic; and, no doubt, the urea in the urine is very much diminished in this disease; but the disease is not at all like the ordinary uræmic eclampsia. Yet, it is true, parenchymatous degeneration of the kidney is found along and corresponding with parenchymatous degeneration of the liver."

The author then contrasts the effects of heart disease, especially of mitral regurgitation, on the pregnant uterus, tending to expel the living fœtus, with those of icterus gravis, tending to kill the foetus and retain it in the uterus.

The case forming the subject of the lecture is then related-one of acute yellow atrophy in the third month of pregnancy ending fatally. "Liver, on section, yields an emphysematous feeling;... highly emphysematous (not putrid), its section resembling that of highly-aërated bread. . . Kidneys flabby, with large air-blebs under the capsule and air-vesicles on section; structure very indistinct, but presents evidence of congestion of cortex and base of pyramids."

The author then contrasts the disease with uræmia.

The passages, which I have marked in italics, show plainly that Dr. Matthews Duncan did not confine his remarks to the liver; that the condition of the blood is, in his opinion, a chief part of the cause of the diseases of the kidney as well as of the liver in pregnancy; and that, in short, his description is one of what he would have called "toxæmia" (as he called another affection "sapræmia") if the name had occurred to him. This was in 1879 .

As regards the neurotic variety of vomiting, it is plainly set forth in the above extract. It probably had been "discovered" in prehistoric times, though the name is comparatively modern. Indeed, no one can treat the condition properly on any other hypothesis.

The latter part of Dr. Whitridge Williams's paper is concerned with his interesting work on the toxamias of pregnancy, which has excited the interest of the medical world, and which must always form a part of the literature of a very important and obscure chapter in medicine, though the relation of the ammonia coefficient to toxæmia still requires confirmation and elncidation.

The portions of the paper which I have ventured to criticise are, first the inclusion of the author's first class, for which $I$ believe that there is no necessity. In my experience "Reflex" cases are either instances of faulty logic, or properly belong to Class 2 ("Neurotic").

I have a further practical objection to the recognition of this class in the effect which it produces on practice. In my opinion the cases which would, according to the "Reflex" theory, be treated by posture, pessaries, cauterization of the cervix, and partial dilatation of the os internum, are far better and more successfully treated by good advice, healthy surroundings, a sensible nurse, and-if you 
will-the personal influence kuown as "suggestion," belonging as they do to the "neurotic" variety. Severe cases of this kind may require something further, of which I shall speak later.

The next criticism which I have to make concerns the credit assigned to the late Dr. Matthews Duncan. The extract speaks for itself. He divides severe vomiting of pregnancy into two classes: neurotic and toxic, though he does not use either word, neither having been invented in 1879 . But, in all essential respects, we have in the work quoted the truth as now generally accepted. If Dr. Duncan's views on the toxæmic varjety were obscured by writers who "darkened counsel by words without knowledge," that was not his fault. If his views obtained "little if any recognition" in the general medical world, that is only to the discredit of the general medical world. Also, it surely is overstating the case to say: "Matthews Duncan, in 1879, pointed out that the condition (Vomiting of Pregnancy) was sometimes associated with serious hepatic disorders, but this was not generally recognized until the work of Stone, Ewing and myself (Whitridge Williams) showed that in many of the fatal cases lesions were present in the liver identical with those occurring in acute yellow atrophy."

Surely Dr. Whitridge Williams's real claim is that, by the advantage of juniority, he has been enabled, through the possession of modern methods, used with great scientific discernment, to confirm and elucidate the views of Matthews Duncan-a man, by the way, whom no one need be ashamed to follow.

If Duncan's views obtained little recognition in the general medical world, it is nevertheless true that ever since he published his work quoted above, his teaching has been endorsed at least by the present writer, first at St. George's Hospital (1881 to 1891), and (since 1891) at Duncan's old school (where he had the honour of succeeding him), and has formed part of the traditions of that schoolI mean St. Bartholomew's Hospital. If I may be allowed to state what that teaching has been, I would summarise it as follows:-

Vomiting of pregnancy falls into two groups, which should be carefully distinguished, both as regards treatment, and as regards prognosis: namely, (1) those due to neurosis; (2) those due to poisoning. Those due to neurosis do not, generally, threaten life; those due to poisoning do. Those due to neurosis can, generally, be cured by appropriate treatment; those due to poisoning, when severe, require the immediate interruption of pregnancy, which procedure, however, may fail to save the patient. A long experience enables me to affirm that toxæmic vomiting of pregnancy is of the greatest rarity, and that a man may well fail to see a single case in a practice extending over many years.

I may illustrate the two classes by two cases:- 
(1) Mrs. M., seen by me December 11th, 1901, in consultation, in one of the northern counties of England, for very severe vomiting of pregnancy, thought to threaten life and to indicate abortion. Age 27, married 3 years, one child Septomber 1899; says she has had two miscarriages, the last after uterine treatment by a doctor who wanted to curette her.

Temperament nervous, two of mother's brothers insane, busband has a lawsuit, says she is not worried. Last catamenia ended September 20th. November 20th vomiting began; November 23 it became very violent, it is alleged after an indigestible meal followed by a chill. December 3rd rectal feeding was begun, but feeding by the mouth was not stopped.

The temperature has been irregular; on December 6th it reached 102 ; it has generally ranged between $9 \% \cdot r$ and $99 \%$. Pulse 110 , thin, regular.

Urine 1025, no albumen, no sugar.

No jaundice; tongue olean; uterus fully the size of 3 months, os rather patulous, body rising into abdomen, pelvis natural.

Opinion: neurotic vomiting.

I decided to treat the case like one of delixium tremens, with large doses of bromide (a method which I have since followed with good results, and which I had never seen recommended.) Feeding to be exelusively by the rectum, the nutrient enema to consist of 3 ounces of peptonised milk with 40 grains of potassinm bromide every 4 hours for 24 hours or longer, the bromide being given only if the patient was awake. Being confident of the variety of vomiting present, I gave a good prognosis.

I have not described the vomiting, which was, however, vory violent and the patient was extremely excited.

The vomiting ceased entirely within 24 hours and did not return. About December 13th a trace of sugar was found in the urine, but no albumen.

I may say that I have never been obliged to interrupt pregnancy for neurotic vomiting and that I believe that its necessity is of the greatest rarity.

The object of the bromide is to abolish reflexes, and to make an absolute break in the continuity of consciousness; the patient must be kept asleep the whole time.

(2) Mrs. W., æet. 36, seen in the country, in consultation, November 23rd, 1886. Pregnancies $=4$; labours $=4$.

This pregnancy had advanced about 7 weeks; vomiting began 3 weeks after the last period and was the first symptom of pregnancy. It was bilious in character, motions bile-stained, emaciation from the onset (the patient was buxom previously), no fever, no albuminuria (as reported). 
The patient was slightly jaundiced, tongue clean, rather dry; pulse very feeble, compressible, 140. Abdomen no tenderness, liver dulness normal. Urine scanty, colour of brown sherry, normally acid, slight floceulent turbidity, sp. gr. 1022; on addition of cold nitric acid no green colour is obtained; a play of green and pink is obtained when two drops are allowed to run together on an opaque white ground; trace of albumen.

Under microscope: blood cells, epithelium cells, pigmented masses, hyaline and epithelial casts; leucin.

A few days previously two local medical men, acting on my advice, given after examination of the urine above, had attempted to procure abortion, without effect, but with relief to the vomiting. $A$ sponge tent produced no effect in dilating the cervix.

I saw the patient, diagnosed the case as due to poison (toxic), and of a serious nature, and decided that the uterus must be emptied to save the patient's life.

The largest laminaria tent (nearly as large as the little finger) produced no dilatation in 131 hours. Hegar's dilators were sent for to London and Nottingham, but were unknown by the instrumentmakers in both places. I therefore got the village carpenter to turn me a set in boxwood, giving him drawings and dimensions. He finished these in a short time, they acted well, and I emptied the uterus quickly and safely. After the operation the pulse was 144 and very feeble indeed. Temperature $97 \cdot 2$. The prognosis appeared bad, but the patient made a rapid recovery.

Matthews Duncan was to a great extent-to use an old English word-a "Seer." Any of my readers who doubt this might do many worse things than read his collected "Clinical Lectures," if they have not already read them; or, if they have, read them again. 